\title{
Comunicação em projetos públicos: uma análise da literatura
}

\section{Communication in public projects: an analysis of the literature}

\author{
MAYARA ALVES RAMOS \\ Universidade Federal do Cariri \\ JENIFFER DE NADAE \\ Universidade Federal do Cariri
}

\section{RESUMO}

Este trabalho tem por objetivo analisar a literatura internacional sobre comunicação em projetos do setor público, por meio de uma análise bibliométrica e de conteúdo aferindo os índices de produção e difusão de conhecimento científico, com uma amostra composta de 194 artigos, extraídos da base de dados Scopus, de publicações entre os anos de 2007 e maio de 2018. Tem-se por principal contribuição oferecer como produto um levantamento do estado da arte acerca da comunicação em projetos públicos, visando auxiliar os pesquisadores que possuem interesse de estudo no tema selecionado, com a identificação das barreiras de comunicação levantadas e o canal de comunicação citado, levantando questionamentos acerca de trabalhos futuros que podem vir a ser empreendidos. Observou-se principalmente que a comunicação no gerenciamento de projetos do setor público ainda sofre de carência, no aspecto ampliação dos estudos acerca desse tema, além da identificação acerca das barreiras que apontam à aspectos desde a falta de interação entre os envolvidos, fatores sociais e de relacionamento, assim como a falta do registro da informação comunicada e a sua disseminação aos stakeholders. Palavras chave: Comunicação; Gestão de Projetos; Setor Público; Bibliometria; Barreiras de Comunicação.

\section{Abstract}

This paper article aims to analyze the international literature on communication in public sector projects, through bibliometric 
analysis and evaluation of the contents of the indexes of production and dissemination of scientific knowledge, with a sample composed of 194 articles extracted from the Scopus database, of publications between the years of 2007 and May of 2018. Its main contribution is to offer like product a study of the state of the art on the communication in public projects, aiming to assist the researchers that have interest of study in the selected theme, with the identification of the communication barriers raised and the channel of communication cited, raising questions about future paper article that can be done. It was observed, above all, that communication in project management of the public sector still suffers from scarcity, in the aspect of expansion of the studies on the subject, besides the identification on the barriers that point to the aspects from the lack of interaction between the involved, social factors and also the lack of registration of the information communicated and its disclosure to the stakeholders.

Keywords: Communication; Project Management; Public Sector; Bibliometric Analysis; Communication Barriers.

\section{INTRODUÇÃo}

O êxito de um projeto, dentre outros fatores, está relacionado a gestão da comunicação existente na organização e consequentemente na mitigação das barreiras comunicativas, como as causadas pelas conotações, diferenças de entonação, diferenças de tolerância ao conflito e métodos para resolvê-los (SILVA et al., 2018).

PMI (2017), define comunicação como a troca de informações, intencional ou involuntária, ou seja, informações trocadas podem estar em forma de ideias, instruções ou emoções. Assim, pessoas interagem por meio de canais comunicativos em todos os ambientes da sociedade, no entanto, a transformação da comunicação por causa da chegada de novos meios de comunicação eletrônica é notada, mas o impacto disso nas organizações não é claramente entendido (SMIT et al., 2017).

Para a promoção do gerenciamento do fluxo informacional dentro de um projeto, a criação e manutenção de meios comunicativos são necessários, pois, o projeto está sujeito às barreiras, ruídos ou interferências que são fatores inibidores da eficácia da comunicação, descaracterizando a mensagem e o objetivo pretendido (HEDLER et 
al., 2015), sendo que as barreiras de comunicação são um conjunto de fatores que impedem ou dificultam a recepção da mensagem no processo comunicacional (ABREU; BAZONI, 2016).

A função da comunicação na formulação e realização de táticas administrativas possui função primordial com projetos, além disso, o gerente de projetos precisa buscar estratégias que possam englobar os diferentes níveis organizacionais e fazer com que a informação chegue aos demais stakeholders de forma simples e de fácil compreensão, de forma que é por meio da comunicação que ocorre a transferência e a disseminação das normas de conduta, dos valores, da missão e dos objetivos organizacionais (HEDLER et al., 2015).

Para os projetos do setor público, o estabelecimento de canais de comunicação eficientes corresponde a um dos principais desafios para a concretização de projetos, uma vez que a Administração pública, que se traduz nas ações dos governos, vem passando por mudanças ao longo dos tempos, especialmente motivadas pela globalização e pela exigência dos cidadãos que passaram a exigir serviços públicos de qualidade (ALMEIDA, 2015). Na administração pública é habitual a existência de grandes obstáculos em relação ao fluxo de informações e à troca de informações entre os seus colaboradores (SOUZA; RODRIGUES, 2012).

Dessa forma, o objetivo deste trabalho é analisar a literatura internacional sobre comunicação em projetos do setor público, em um estudo quantitativo por meio da aferição dos índices de produção e difusão de conhecimento científico oriundos de um estudo bibliométrico, com uma amostra composta de 194 artigos, extraídos da base de dados Scopus, utilizando publicações registradas entre os anos de 2007 e maio de 2018.

O presente artigo está organizado em cinco seções: na seção 1 o tema para este estudo foi abordado e contextualizado, assim como, o objetivo foi estabelecido; a seção 2 compreende no referencial teórico empregue por este; a seção 3 corresponde aos procedimentos metodológicos utilizados na formulação do mesmo; a seção subsequente 4, apresentam questões gerais observadas no desenvolvimento; e por fim, na seção 5 as conclusões do estudo foram apresentadas. 


\section{REFERENCIAL TEÓRICo}

Projeto pode ser considerado como uma série de atividades que tem um objetivo próprio a ser alcançado dentro de determinadas especificações, com datas de início e término definidos, com orçamento específico, além de possuir recursos e composto por equipes multifuncionais (KERZNER, 2009).

Dessa forma, o gerenciamento de projetos é realizado através da aplicação e integração apropriados dos processos de gerenciamento de projetos identificados para o projeto (PMI, 2017). Em torno dessa gestão, a comunicação dentro de um projeto é gerida em duas partes, sendo a primeira a partir do desenvolvimento de uma estratégia que visa garantir que a comunicação seja eficaz para os stakeholders e a segunda realiza as atividades necessárias para implementar a estratégia de comunicação (PMI, 2017).

O gerenciamento das comunicações do projeto envolve as atividades que facilitam a criação de informações, distribuição, recebimento, reconhecimento e compreensão (YAP; ABDUL-RAHMAN; CHEN, 2017), contribuindo para o entendimento acerca da comunicação como ferramenta que propicia o alcance aos objetivos, a comunicação desenvolve os relacionamentos necessários para resultados bem-sucedidos de projetos e programas (PMI, 2017), além de considerar a comunicação eficaz como uma faceta importante do gerenciamento baseado em projetos, ela é considerada o pré-requisito essencial para o gerenciamento bem-sucedido de projetos (YAP; ABDUL-RAHMAN; CHEN, 2017).

As características significativas do projeto que se correlacionam com o sucesso incluem a definição do escopo, cronograma, orçamento e a complexidade do projeto (MOLENAAR; SONGER; ASCE, 1998), complexidade essa que define o grau de comunicação entre os membros engajados diretamente no projeto e os seus stakeholders, ou partes interessadas. Portanto, a comunicação efetiva é crucial para o controle de tempo e custo (YAP; ABDUL-RAHMAN; CHEN, 2017).

De acordo com o conteúdo a ser comunicado, os stakeholders devem receber tal mensagem se esta gerar impacto no projeto. Como se identifica quando a informação terá um impacto direto no projeto? Normalmente, se algo afetar o escopo, o tempo, o custo, o risco ou a qualidade de uma tarefa, isso justifica a escalada através 
dos canais de comunicação apropriados (ČULO; SKENDROVIĆ, 2010). À medida que um projeto se desenvolve, o gerente de projeto precisará melhorar as habilidades básicas de comunicação para se tornar mais eficiente na comunicação (ZULCH, 2014).

Em seu nível mais básico, a comunicação possui três componentes: um transmissor (emissor), um canal de transmissão (meio) e um receptor (ZULCH, 2014), no entanto, o impacto e as consequências das comunicações do projeto devem ser avaliados e monitorados com cuidado para garantir que a mensagem com o conteúdo certo, seja entregue ao público na hora correta e pelo canal de comunicação adequado (PMI, 2017). Sem uma comunicação eficaz, um gerente realiza pouco (ZULCH, 2014), assim, a comunicação deve ser realizada de maneira oportuna e feita com frequência (LING; MA, 2014.

O canal de comunicação mais comum é o falar, por ser imediata, espontânea, direta (ZULCH, 2014), embora possa sofrer ruídos, visto que o ruído é qualquer coisa que perturbe a comunicação, incluindo as atitudes e emoções do receptor (ABREU; BAZONI, 2016), ou seja, qualquer fonte de erro, distúrbio ou deformação da fidelidade na comunicação de uma mensagem, seja ela sonora, visual, escrita, etc. (GIL, 2006), ponderando ainda suas variações, que podem decorrer do emissor, bem como do receptor. O Quadro 1 mostra os tipos mais comuns dessas variações.

Quadro 1. Ruídos na comunicação e suas variantes mais comuns

\begin{tabular}{|c|c|}
\hline RUÍDOS & TIPOS MAIS COMUNS \\
\hline $\begin{array}{l}\text { Decorrentes do } \\
\text { emissor }\end{array}$ & $\begin{array}{l}\text { - Falta de clareza nas ideias; } \\
\text { - } \text { Comunicação múltipla; } \\
\text { - } \text { Problemas de codificação; } \\
\text { - Háqueio emocional; } \\
\text { - Suposição acerca do receptor. }\end{array}$ \\
\hline $\begin{array}{l}\text { Decorrentes do } \\
\text { receptor }\end{array}$ & $\begin{array}{l}\text { - } \text { Audição seletiva; } \\
\text { - } \text { Aesinteresse; } \\
\text { - } \text { Preocupaçąa premão com a resposta; } \\
\text { - } \text { Crenças e atitudes; } \\
\text { - Reação do emissor; } \\
\text { - } \text { Preconceitos e estereótipos; } \\
\text { - } \text { Atribuição de intenções; } \\
\text { - Comportamento defensivo. }\end{array}$ \\
\hline
\end{tabular}

Fonte: Os autores. Adaptado de Gil (2006, p. 74-77) 
A comunicação é o caminho a ser utilizado para alcançar os objetivos compreendidos como fatores de sucesso na execução do projeto, que são altamente dependentes de um estilo de comunicação organizacional eficaz (CYGANCZUCK; JUNIOR; JUNIOR, 2017). Não obstante, a compreensão acerca dessa comunicação está cercada de barreiras, das quais impedem que ocorra a fruição das informações. A comunicação aparece como mediadora da tensão decorrente, atuando como fiel balança entre creativity (o que se deseja fazer) e constraint (o que deve ser feito) (ROMAN, 2009).

Dessa forma, os fluxos de informação e conhecimento são, portanto, um resultado da ferramenta de comunicação escolhida, bem como as características do processo de comunicação (ADENFELT, 2009), para tanto, a existência de barreiras de comunicação impedem a fluidez das informações dentro de um projeto, sendo estas barreiras, definidas como todas as barreiras que limitam a quantidade de desenvolvimento de conhecimento sobre desenvolvimento organizacional e desenvolvimento de sistemas no projeto (ANDERSSON, 2016).

De acordo com o estudo de Cyganczuck, Junior \& Junior (2017), as principais barreiras de comunicação identificadas com os gerentes de projetos de seu estudo são a falta de feedback aos integrantes da equipe de projetos; a falta de confiança entre os membros da equipe; a transmissão de informações equivocadas e distorcidas; a falta de envio da informação ou envio em momentos inoportunos; e as competências e conhecimentos limitados dos gerentes de projetos, representando uma liderança fraca.

Em particular aos projetos do setor público, as barreiras de comunicação são ocasionadas por diversos os motivos que desencadeiam este tipo de procedimento indesejável, que vão desde a falta de conhecimento técnico, até a preocupação com a manutenção do seu emprego (SOUZA; RODRIGUES, 2012). Ademais, os desdobramentos de tais práticas acarretam danos ao serviço público, pois afeta sobremaneira o processo de comunicação, que é fundamental na persecução do sucesso da gestão de projetos (SOUZA; RODRIGUES, 2012).

A comunicação atua, então, nas políticas públicas como um meio necessário para a divulgação das etapas e a mobilização dos 
envolvidos (CEZAR, 2018), pois, não basta que as informações sejam repassadas, elas precisam ser compreendidas por todos os envolvidos no projeto (QUADROS; CARVALHO, 2012). Nos projetos do setor público a comunicação, pode ser realizada dentro do projeto como também para a comunidade na qual está inserida, no entanto, apesar de, por definição, ser usada para comunicações que se baseiam em uma visão simplificada e unilateral do ambiente (BOGDAL, 2013), esta sofre desvantagem por não receber um feedback direto de seus stakeholders, dessa forma, tal ramo da administração compreende em promover a manutenção dos serviços exercidos pelo setor jurídico, órgãos e agentes públicos (FILHO, 2015).

\section{Procedimentos Metodológicos}

A realização de um trabalho bibliométrico resulta na elaboração de um estudo focado em explorar, ordenar, investigar grandes amostras de informações históricas, das quais revelam aos pesquisadores padrões anteriormente não observados, tais modelos podem ser utilizados como base para futuras tomadas de decisões. Bibliometria pode ser entendida como uma ferramenta capaz de proporcionar a medida de textos e informações (NORTON, 2001), sendo a mesma empregada para o entendimento da discussão sobre o panorama de determinado tema (MORRIS et al., 2002; VIEIRA, 2007).

Os estudos bibliométricos podem colaborar na tarefa de sistematizar as pesquisas realizadas num determinado campo de saber e endereçar problemas a serem investigados em pesquisa futuras (CHUEKE; AMATUCCI, 2015).

Com o presente estudo buscou-se analisar a produção científica internacional acerca do tema, considerando o método da bibliometria e a análise de conteúdo dos artigos selecionados para tal pesquisa. A base de dados utilizada foi a Scopus, uma vez que é o maior banco de dados de resumos e citações da literatura revisada por pares: periódicos científicos, livros e anais de congressos (SCOPUS, 2018).

A coleta de dados ocorreu em maio de 2018, e com a finalidade de estruturação do estudo, adotou-se como etapas de pesquisa a seleção dos termos, posteriormente, restringiu-se para os idiomas Inglês e Português, selecionando apenas artigos e do período de 2007 a 2018. A Figura 1, apresenta as etapas da pesquisa. 
Figura 1. Etapas de Pesquisa

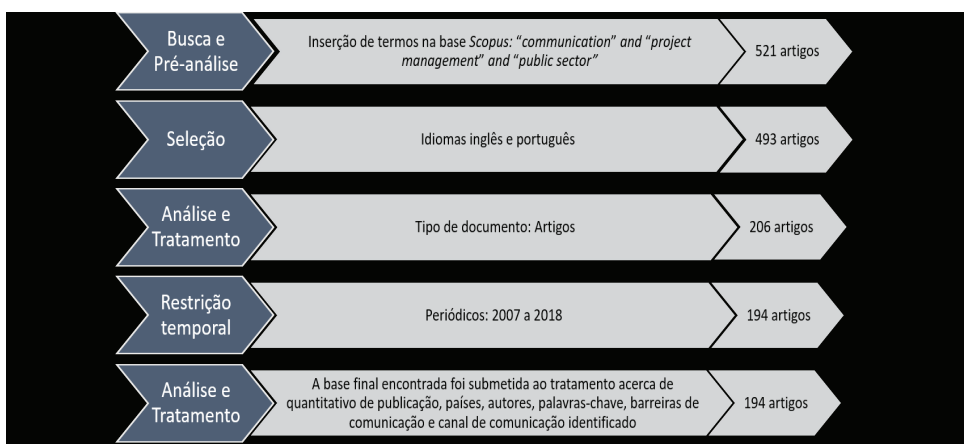

Fonte: Os autores

Para as análises, utilizou-se softwares para auxílio no tratamento dos dados, a exemplo do Microsoft Excel para construção de planilhas, tabelas, quadros e gráficos diversos que serão utilizadas para evolução da produção, principais periódicos e autores, já o VosViewer, que é uma ferramenta para a construção e visualização de redes bibliométricas, nas quais podem incluir, periódicos, pesquisadores ou publicações individuais (VosViewer, 2019), fora utilizado para gerar redes de palavras-chave e de co-citação.

Inicialmente fora realizada a coleta dos dados, contendo a amostra específica de informações das publicações fornecidos pela Scopus. Após, buscou-se a identificação dos artigos mais citados da base, realizando a exposição das informações utilizando gráficos de barras, por exemplo, destacando também um indicador de citação, o Fator de Impacto. Para os artigos mais citados, realizou-se uma análise detalhada em busca de menções das barreiras existentes na comunicação dos projetos, além de checar se houve citação acerca dos canais de comunicação adequados no projeto utilizado.

\section{Apresentação e Análise dos Resultados}

A partir da amostra selecionada, observando os aspectos metodológicos empregados neste estudo, buscou-se realizar uma síntese diante das principais informações que puderam ser extraídas as principais considerações levantadas acerca da produção científica 
acerca do tema entre os anos de 2007 e maio de 2018, concretizando assim os últimos 11 anos de produção.

Iniciando as análises, observa-se que a Figura 2 apresenta a evolução do quantitativo de produções ao longo dos anos, com destaque para o ano de 2017 que apresenta o maior ano com publicações, 27 no total. Os primeiros artigos sobre o tema datam do ano de 2007 e falam acerca de aspectos relacionados a sistemas de informações em governos; projetos de melhoria de serviços de saúde; além de um artigo que trata abordagens de gestão costeira e um artigo que versa acerca de estratégias com stakeholders. Com uma média de publicações anual para o período de 19,4 publicações, 2018 conta com apenas três publicações em virtude do período no qual a coleta de dados foi feita, que falam acerca de melhoria e implementação de melhorias em serviços de saúde e definição de necessidades de desenvolvimento de pessoas em projetos de infraestrutura na Nigéria.

Figura 2. Evolução da quantidade de publicações por ano a partir de 2007

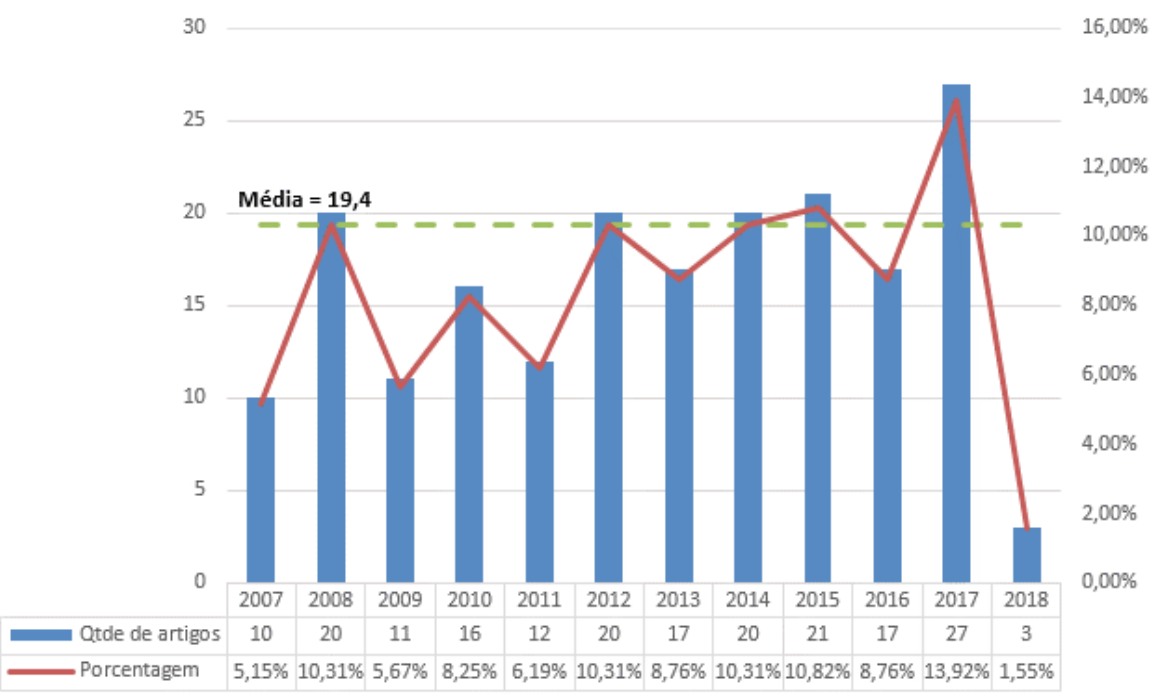

Fonte: Os autores. 
Contando com três publicações para o ano de 2018 como já fora mencionado, o Quadro 2 apresenta os objetivos de cada artigo.

\section{Quadro 2. Resumo das publicações de 2018}

\begin{tabular}{|c|c|c|c|c|}
\hline TITULO DO ARTIGO & $\begin{array}{l}\text { JORNAL/ } \\
\text { REVISTA }\end{array}$ & AUTORES & PAIS & OBJETIVO \\
\hline $\begin{array}{l}\text { British Columbia Ministry of } \\
\text { Health Patients as Partners: A } \\
\text { transformational approach }\end{array}$ & $\begin{array}{c}\text { Healthcare Management } \\
\text { Forum }\end{array}$ & $\begin{array}{l}\text { Bar S., Grant K., Asuri } \\
\text { S., Holms S., (2018). }\end{array}$ & Canadá & $\begin{array}{c}\text { Relatar o caso acerca da metodologia } \\
\text { de um projeto de colaboração para a } \\
\text { melhoria dos serviços em saúde } \\
\text { públicos. }\end{array}$ \\
\hline $\begin{array}{l}\text { A model for implementing } \\
\text { sustainable mHealth } \\
\text { applications in a resource- } \\
\text { constrained setting: A case of } \\
\text { Malawi }\end{array}$ & $\begin{array}{l}\text { Electronic Joumal of } \\
\text { Information Systems in } \\
\text { Developing Countries }\end{array}$ & $\begin{array}{l}\text { Pankomera R, van } \\
\text { Greunen D., (2018). }\end{array}$ & Africa do Sul & $\begin{array}{l}\text { O estudo de caso apresenta a } \\
\text { implementação de projeto de } \\
\text { aplicativos de saúde móvel para prover } \\
\text { serviços de saúde. }\end{array}$ \\
\hline $\begin{array}{l}\text { Infrastructure procurement } \\
\text { skills gap amongst } \\
\text { procurement personnel in } \\
\text { Nigeria public sector }\end{array}$ & $\begin{array}{l}\text { Joumal of Engineering, } \\
\text { Design and Technology }\end{array}$ & $\begin{array}{l}\text { Mahamadu A.-M., Manu } \\
\text { P., Booth C., Olomolaiye } \\
\text { P., Colker A., Ibrahim A, } \\
\text { Lamond J., (2018) }\end{array}$ & Reino Unido & $\begin{array}{l}\text { Determinar as necessidades de } \\
\text { desenvolvimento de habilidades } \\
\text { criticas de pessoas do setor público } \\
\text { envolvido na aquisição de projetos de } \\
\text { infra-estruturas na Nigéria. }\end{array}$ \\
\hline
\end{tabular}

Fonte: Os autores.

Diante do apresentado, observa-se que de modo geral os artigos do ano de 2018 tratam de projetos que implementam soluções para o serviço de saúde de projetos públicos da área de saúde.

As publicações foram analisadas através da perspectiva do quantitativo de publicações por países sendo o tema do Gráfico 1, nele é apresentado o somatório das produções analisadas de acordo com seus respectivos países. Para a sua construção foram considerados apenas as nações com quatro ou mais publicações sobre o tema.

De acordo com as informações gráficas, observa-se que os Estados Unidos corresponde ao país com maior número de publicações (41 publicações). Com média por país de 11,5 de publicações, o país com menor número de publicações é a China com 4 publicações. Abrindo destaque para o Brasil, que apresenta 5 publicações, o Quadro 3 apresenta os objetivos de cada artigo. 
Gráfico 1. Quantitativo de produção por país com mais de 4 publicações. 50

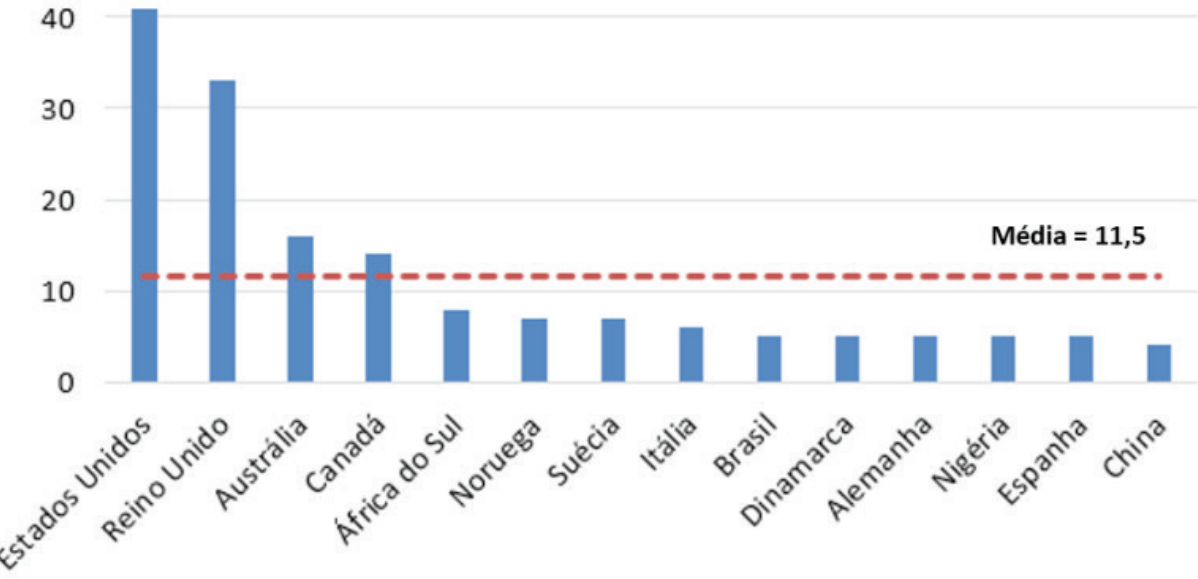

Fonte: Os autores.

Quadro 3. Resumo das publicações em periódicos

brasileiros apresentados na base

\begin{tabular}{|c|c|c|c|}
\hline TÍTULO DO ARTIGO & JORNAL/REVISTA & AUTORES & OBJETIVO \\
\hline $\begin{array}{l}\text { A participação e a capacitação } \\
\text { profissional do setor privado nos } \\
\text { projetos de desenvolvimento } \\
\text { sustentável de municipios da } \\
\text { fronteira sul do estado do Mato } \\
\text { Grosso do Sul }\end{array}$ & $\begin{array}{l}\text { Revista Brasileira de } \\
\text { Gestão e } \\
\text { Desenvolvimento } \\
\text { Regional }\end{array}$ & Frescura E.C.G. (2007) & $\begin{array}{l}\text { Verificar a contribuição do setor privado } \\
\text { nos projetos de Desenvolvimento } \\
\text { Sustentável, planejados pelo setor público e } \\
\text { ações próprias desenvolvidas pelas } \\
\text { organizações. }\end{array}$ \\
\hline $\begin{array}{c}\text { A gestão da inovação na educação a } \\
\text { distância }\end{array}$ & $\begin{array}{l}\text { Revista de Gestão e } \\
\text { Produção }\end{array}$ & $\begin{array}{l}\text { De Araújo E.M., De } \\
\text { Oliveira Neto J.D., } \\
\text { Cazarini E.W., Oliveira } \\
\text { S.R.M. (2013) }\end{array}$ & $\begin{array}{l}\text { Descrever pontos fundamentais para a } \\
\text { análise da inovação em Educação a } \\
\text { Distância que envolve os subsistemas e } \\
\text { componentes do planejamento estratégico. }\end{array}$ \\
\hline $\begin{array}{l}\text { O caso do PAC Embrapa: requisitos } \\
\text { de uma gestão orientada para } \\
\text { resultados no setor público }\end{array}$ & $\begin{array}{c}\text { Revista de } \\
\text { Administração Publica }\end{array}$ & $\begin{array}{l}\text { Porpino G., De Stefani E. } \\
\text { (2014) }\end{array}$ & $\begin{array}{l}\text { Analisar a implantação do Programa de } \\
\text { Fortalecimento e Crescimento da Embrapa } \\
\text { (PAC Embrapa) }\end{array}$ \\
\hline $\begin{array}{l}\text { TeamWork: Uso de groupware para } \\
\text { processos de projetos de engenharia } \\
\text { e arquitetura no serviço público }\end{array}$ & Revista Espacios & $\begin{array}{c}\text { Hatakeyama K., Misaghi } \\
\text { M., Souza da Silva R. } \\
\text { (2016) }\end{array}$ & $\begin{array}{l}\text { Construir um meio de colaboração de } \\
\text { abertura dos recursos, conduzido e } \\
\text { alimentado pelos colaboradores, a } \\
\text { comunidade e utilizando tecnologia de } \\
\text { vanguarda. }\end{array}$ \\
\hline $\begin{array}{c}\text { O sentido da relação trabalho e } \\
\text { saúde para os assistentes em } \\
\text { administração de uma universidade } \\
\text { pública federal no Estado de Minas } \\
\text { Gerais }\end{array}$ & $\frac{\text { Physis: Revista de }}{\underline{\text { Saúde Coletiva }}}$ & $\begin{array}{l}\text { de Faria R.M.O., Leite } \\
\text { I.C.G., da Silva G.A. } \\
\text { (2017) }\end{array}$ & $\begin{array}{c}\text { Analisar o sentido da relação trabalho e } \\
\text { saúde para os assistentes em administração } \\
\text { de uma instituição pública de ensino } \\
\text { superior no Estado de Minas Gerais - } \\
\text { Brasil. }\end{array}$ \\
\hline
\end{tabular}

Fonte: Os autores 
Acerca dos periódicos, a Tabela 1 apresenta os dados referentes às produções de artigos por periódicos, sendo considerados para esta análise apenas os que possuem três ou mais publicações acerca do tema, o quantitativo numérico e o fator de impacto do ano de 2017.

Tabela 1. Análise dos principais periódicos com

3 ou mais publicações sobre o tema.

\begin{tabular}{|c|c|c|}
\hline Periódicos & \# Artigos & $\begin{array}{l}\text { Fator de } \\
\text { Impacto }\end{array}$ \\
\hline International Journal of Public Sector Management & 7 & 1.387 \\
\hline $\begin{array}{l}\text { Transforming Government: People, Process and } \\
\text { Policy }\end{array}$ & 6 & 2.138 \\
\hline $\begin{array}{l}\text { International Journal of Managing Projects in } \\
\text { Business }\end{array}$ & 5 & 1.432 \\
\hline Agriculture and Food Security & 3 & 1.667 \\
\hline BMC Health Services Research & 3 & 1.742 \\
\hline $\begin{array}{l}\text { Engineering Construction and Architectural } \\
\text { Management }\end{array}$ & 3 & 1.838 \\
\hline $\begin{array}{l}\text { International Journal of Health Planning and } \\
\text { Management }\end{array}$ & 3 & 0.721 \\
\hline International Journal of Project Management & 3 & 4.650 \\
\hline
\end{tabular}

Fonte: Os autores

Analisando os periódicos, o International Journal of Public Sector Management, periódico com mais publicações sobre o tema, tem em seu escopo pesquisas relacionadas às questões comuns a administradores e formuladores de políticas do setor público, de forma a proporcionar melhoria da eficiência e eficácia em cenários onde os recursos são escassos e as expectativas da população demonstra-se cada vez maior, além de abordar também serviço civil, saúde e educação, governo local e organizações paraestatais.

O Transforming Government People Process and Policy aborda temas relacionados à transformação do governo por meio de pessoas, processos e políticas. Esta procura apoiar pesquisadores iniciantes, líderes acadêmicos, profissionais e formuladores de políticas para que estes contribuam, gerenciam e compartilhem seus conhecimento e experiência profissionais.

Com seu primeiro volume publicado em 2008, o International Journal of Managing Projects In Business tem o intuito de promover a teoria, pes- 
quisa e prática de todos os aspectos do gerenciamento de projetos. Seus principais objetivos centram-se em compreensão da gestão de projetos e encorajamento de publicação, contendo novas ideias no campo do gerenciamento de projetos, aplicando abordagens multidisciplinares embasadas nas ciências sociais.

A Agriculture and Food Security abriga pesquisas em segurança alimentar, priorizando pesquisas que proporcionem sistemas agrícolas e alimentares mais sustentáveis dos quais resolvam a insegurança alimentar e nutricional local, regional, nacional e / ou global. Seus campos de pesquisa envolvem desde ciências agrárias e ambientais, pecuária, ciências pesqueiras, até saúde pública em relação à condição de segurança alimentar e nutricional.

O periódico BMC Health Services Research tem em seu escopo pesquisas sobre todos os aspectos dos serviços de saúde, incluindo prestação de cuidados, gerenciamento de serviços, avaliação de necessidades, medição de resultados, alocação de recursos, além de abranger temáticas como avaliação de diferentes organizações de serviços de saúde, análise comparativa internacional de sistemas, economia e o impacto das políticas e regulamentações de saúde.

O periódico Engineering Construction and Architectural Management possui escopo embasado em pesquisas e práticas em engenharia, construção e gerenciamento arquitetônico. A mesma abrange o projeto arquitetônico como um todo, gerenciamento de projetos, gerenciamento da construção, gerenciamento de grandes projetos de engenharia e a operação e gerenciamento de instalações construídas.

Caracterizado por abordar questões como a formulação e a implementação de políticas, planejamento e gestão, o International Journal Of Health Planning And Management promove a implementação de centrais de acompanhamento para sistemas e melhoria dos serviços de saúde.

Original do Reino Unido, o International Journal Of Project Management possui escopo baseado nas categorias de Negócios, Gestão, Contabilidade, Empresarial, Gestão Internacional, Gestão de Tecnologia, Inovação e Gestão Ambiental. Oito vezes publicado ao ano proporciona uma base para a expertise mundial nas técnicas, práticas e áreas de pesquisas anteriormente citadas. 
Em suma, dentre os periódicos analisados, observou-se que o escopo relacionado à gestão de projetos estão três periódicos, International Journal of Managing Projects in Business, Engineering Construction and Architectural Management e International Journal of Project Management. Para a Gestão Pública como especificidade, os periódicos International Journal of Public Sector Management, Transforming Government People Process and Policy e International Journal of Health Planning and Management. Por fim, os periódicos Agriculture and Food Security, que trata de segurança alimentar, e BMC Health Services Research, que aborda reflexões acerca de serviços em saúde, destoam das demais áreas predominantes.

Acerca das áreas de pesquisa observadas, possuíram destaque Ciências Sociais com um total de 68 artigos, que corresponde a $22 \%$ da amostra, Medicina com 58, Negócios, Gestão e Contabilidade com 48, Ciências Ambientais com 31 e Engenharias com 25.

O Gráfico 2 apresenta as informações compiladas, demonstrando o universo amostra.

Gráfico 2. Publicações por áreas

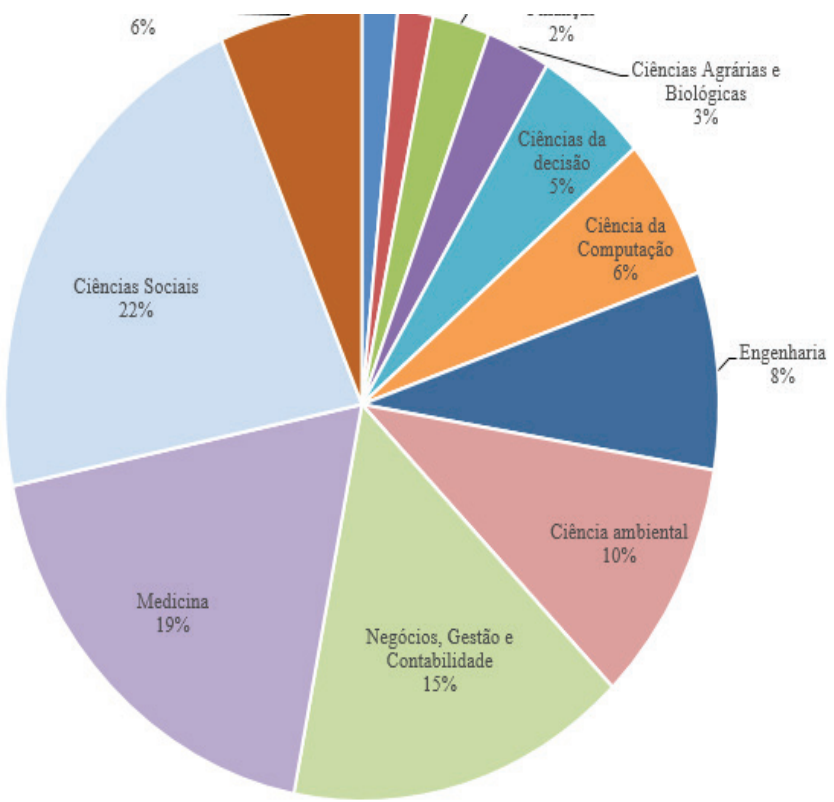

Fonte: Os autores. 
Outro aspecto investigado foram as palavras-chave (Authors Keywords) das publicações, a rede de co-ocorrência de palavras-chave foi gerada, como pode ser observado na Figura 3.

Figura 3. Rede co-ocorrência de palavras-chave

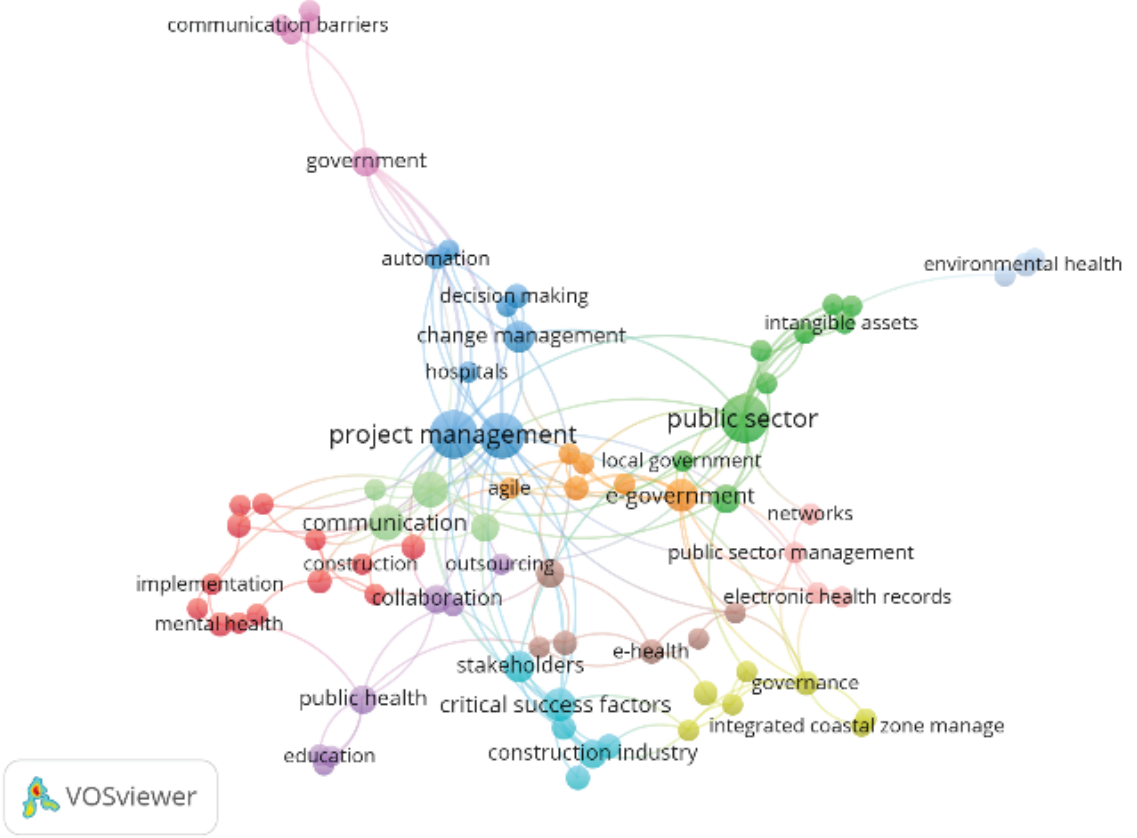

Fonte: Os autores.

O mapeamento foi gerado no VOSViewer, que identificou 679 palavras-chave, utilizou-se para essa formação o mínimo de duas palavras, que contabilizou 92 palavras que atingiam o critério, ainda para que a rede estivesse imparcial, foram excluídas as palavras-chave que identificavam nome de países e metodologia de pesquisa. Os agrupamentos das palavras relacionadas são distintos em clusters de diferentes cores, revelando que esses termos são separados em 12 clusters. O tamanho de cada nó representa a quantidade de ocorrência e a distância entre nós indica o grau de relação entre os itens. Os termos mais utilizados foram: project management, public sector e communication. 
A Tabela 2, mostra de acordo, com enumeração o cluster, a palavra-chave e a quantidade de vezes que foram citadas.

Tabela 2. Co-ocorrência das palavras-chave

\begin{tabular}{|ccc|}
\hline Clusters & Palavras-chave & Ocorrências \\
\hline 1 & Project management & 20 \\
& Management & 10 \\
& Decision making & 4 \\
& Hospitals & 3 \\
& Automation & 3 \\
\hline & Public sector & 28 \\
& Intangible assets & 3 \\
& Local government & 2 \\
\hline 3 & Communication & 27 \\
\hline 4 & Collaboration & 10 \\
& Education & 10 \\
& Public health & 8 \\
& Outsourcing & 2 \\
\hline 5 & Construction & 8 \\
& Mental health & 8 \\
& Implementation & 5 \\
\hline
\end{tabular}

\begin{tabular}{|ccc|}
\hline Clusters & Palavras-chave & Ocorrências \\
\hline 6 & Stakeholders & 6 \\
& Critical success factors & 6 \\
& Construction industry & 4 \\
\hline 7 & Networks & 2 \\
& Public sector management & 2 \\
& Electronic health records & 2 \\
\hline 8 & E-government & 6 \\
& Agile & 2 \\
\hline 9 & Governance & 5 \\
& Integrated coastal zone manage & 2 \\
\hline 10 & Government & 3 \\
& Communication barriers & 2 \\
\hline 11 & Environmental health & 3 \\
\hline 12 & E-health & 2 \\
\hline
\end{tabular}

Fonte: Os autores.

O cluster 1, 2 e 3 expõem acerca das principais palavras que foram mais citadas na base, dessa forma o primeiro cluster reúne os termos que apresenta correlação entre a gestão de projetos, o gerenciamento, a tomada de decisão e cita ainda a automação e hospitais, uma vez que os artigos relacionados a esse cluster referiam-se ao gerenciamento de projetos como método de atuação

O segundo cluster, trabalha acerca das palavras-chave que se ligam diretamente e com maior intensidade ao setor público, assim, fora identificado que os termos "ativos intangíveis" relacionados a "governo local", tornaram esse cluster com característica de um setor público atuando com projetos estratégicos que beneficiem a população.

A "comunicação", no terceiro cluster, destacou-se por ser um dos termos analisados, sua grande importância na rede se deu através da identificação descrita em diversos artigos da base como ponto crucial para o desenvolvimento de o gerenciamento de um projeto.

No cluster 4 , é citada a saúde pública, no entanto ela vem acompanhada de colaboração e educação, ambas palavras ligadas 
à terceirização, uma vez, que no contexto internacional, há uma presença constante de serviços de saúde privados em maior escala, fato que é tema de vários estudos e seguem citados nos clusters 10 e 11, como temas da saúde ambiental e saúde utilizando-se das tecnologias da informação como melhoria contínua.

Os clusters 5 e 6 abordam temas cruciais no gerenciamento de projetos, pois, áreas como a indústria da construção, implementação que está ligada à softwares de gerenciamento de informações nas organizações projetizadas, stakeholders e fatores críticos de sucesso, ambos temas chaves que desenvolvem abordagens com preocupação acerca do adequado andamento do projeto.

Para o cluster 7, o termo "networks" foi um dos aspectos que mais se destaca em artigos que tratam da gestão do setor público. Já o termo "registro eletrônico em saúde", teve grande ocorrência em publicações que os seus respectivos objetivos eram direcionados à análises de casos no setor de saúde.

Para os demais clusters, 8 e 9, as palavras se correlacionaram pela área de sistema de governança eletrônica, por meio da gestão ágil para projetos de tecnologia da informação, e a governança fora relacionada no cluster 9 para realizar a gestão da zona costeira, projetos ligados à Marinha.

Abre-se importante destaque para o cluster 10, que apresenta barreiras de comunicação e governo no mesmo cluster, por ser um tema levantado nas análises desse estudo, pode-se perceber que apenas neste item, as barreiras de comunicação ligadas ao setor público não foram amplamente abordadas na literatura como principal foco das pesquisas, denota-se tal informação pela quantidade de palavras-chave encontradas na base e mais ainda que possuam ligação e correlação à governo/setor público.

Após considerações acerca das palavras-chaves usadas nas publicações, os autores são o objeto das análises seguintes, de acordo com sua quantificação na amostra analisada. Ao identificar os autores com publicações na base, com dois ou mais artigos publicados, conforme Quadro 4, apresenta-se os principais autores, as quantidades de artigos, suas respectivas afiliações, os países que residem e o tema geral do tema das publicações, vale destacar, que o critério inclusão de autores na compilação abaixo, foi a quantidade de artigos por autor. 


\section{Quadro 4. Análise de autores mais frequentes}

\begin{tabular}{|c|c|c|c|c|}
\hline AUTORES & $\begin{array}{c}\text { QTDE } \\
\text { ARTIGOS }\end{array}$ & AFILIAÇÃO & PAÍS & $\begin{array}{c}\text { TEMA DA } \\
\text { PUBLICAÇÃOO }\end{array}$ \\
\hline Ezezika, O.C. & 3 & $\begin{array}{l}\text { McLaughlin } \\
\text { Rotman Center } \\
\text { for Global Health }\end{array}$ & Canadá & $\begin{array}{l}\text { Agricultura e } \\
\text { biossegurança }\end{array}$ \\
\hline Daar, A.S. & 2 & $\begin{array}{l}\text { University of } \\
\text { Toronto }\end{array}$ & Canadá & $\begin{array}{l}\text { Agricultura e } \\
\text { biossegurança }\end{array}$ \\
\hline Furlong, S. & 2 & $\begin{array}{l}\text { John Moores } \\
\text { Liverpool } \\
\text { University }\end{array}$ & Reino Unido & $\begin{array}{c}\text { Gerenciamento } \\
\text { de Projetos para } \\
\text { e-government }\end{array}$ \\
\hline Rosacker, K.M. & 2 & $\begin{array}{c}\text { Minnesota State } \\
\text { University } \\
\text { Mankato }\end{array}$ & $\begin{array}{c}\text { Estados Unidos } \\
\text { da América }\end{array}$ & $\begin{array}{c}\text { Gestão de } \\
\text { projetos em } \\
\text { tecnologia para o } \\
\text { setor público }\end{array}$ \\
\hline
\end{tabular}

Fonte: Os autores.

Destaca-se o Canadá que aparece com dois autores e 5 publicações, os Estados Unidos da América com um autor e duas publicações e o Reino Unido com um autor e duas publicações. Dessa forma, torna-se possível compreender que dentre os autores identificados os temas de interesses de suas pesquisas estão nas áreas de agricultura e biossegurança e gerenciamento de projetos de tecnologia para o setor público.

Outra análise que pode ser feita é em relação a co-citação de autores, Figura 4, na rede gerada pode ser observada os domínios de produção acerca do tema, além de perceber a proximidade entre os autores. O Grupo 1 mostra densidade maior de correlação entre os autores, por ter cinco autores e os nós apresentarem ligação com o Grupo 4 e 5 em maior quantidade. Os Grupo 2 e 3 apresentam ligações de menos densidade e não se ligam com os grupos 4 e 5 . 
Figura 4. Co-citação de autores

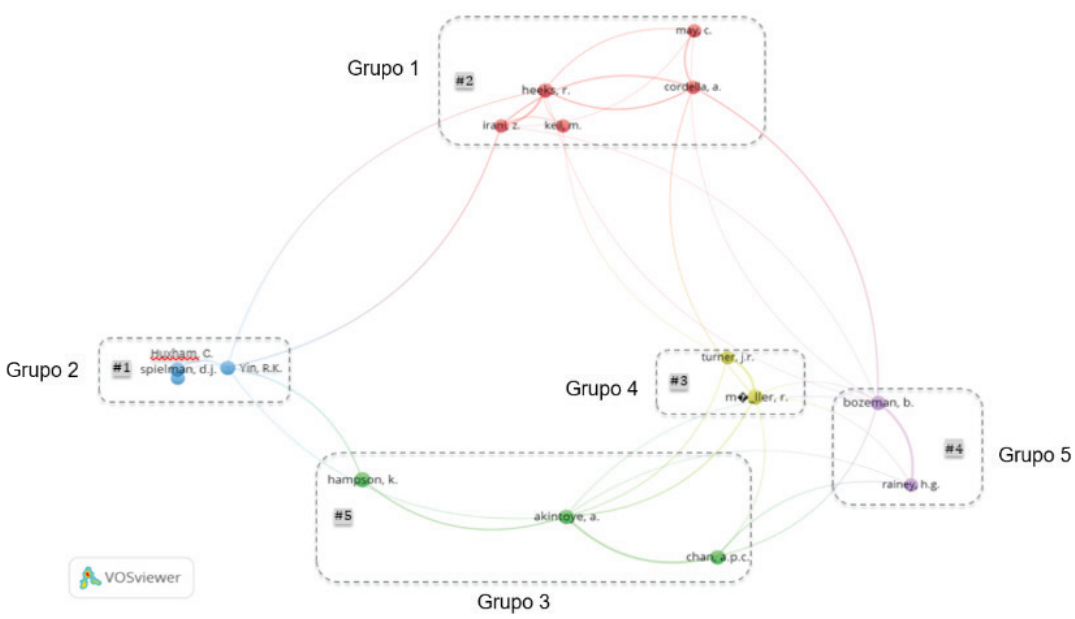

Fonte: Os autores

Assim, os artigos mais citados na base apresentaram uma média de 15,01 de citações, uma mediana que corresponde a 5, além da correspondência entre autores na média e acima dela, dessa forma, os outliers de citação estão representados por seus autores, conforme Figura 5, tendo como o artigo mais citado, cerca de 309 vezes o trabalho de Pretty, Toulmin e Williams (2011), que trata acerca intensificação da agricultura sustentável na África. O segundo trabalho mais citado é o de Hsieh, Rai e Keil (2008), no qual aborda a desigualdade digital em um estudo comparativo acerca do uso continuado por pessoas em situações de vulnerabilidade.

Por fim, a partir da os autores considerados outliers, acima da média 15,01, fora obtido um total 30 publicações inicialmente, e após refinou-se para aqueles foram referenciados por mais de 16 vezes. Então foram submetidos à análise de menção no texto de barreiras de comunicação e se foram identificados canais de comunicação que viessem a minimizar os impactos das barreiras na comunicação dentro do projeto. Assim, obteve-se 10 artigos que atendiam aos critérios, dispostos no Quadro 5. 


\section{Figura 5. Autores considerados outliers de citação}

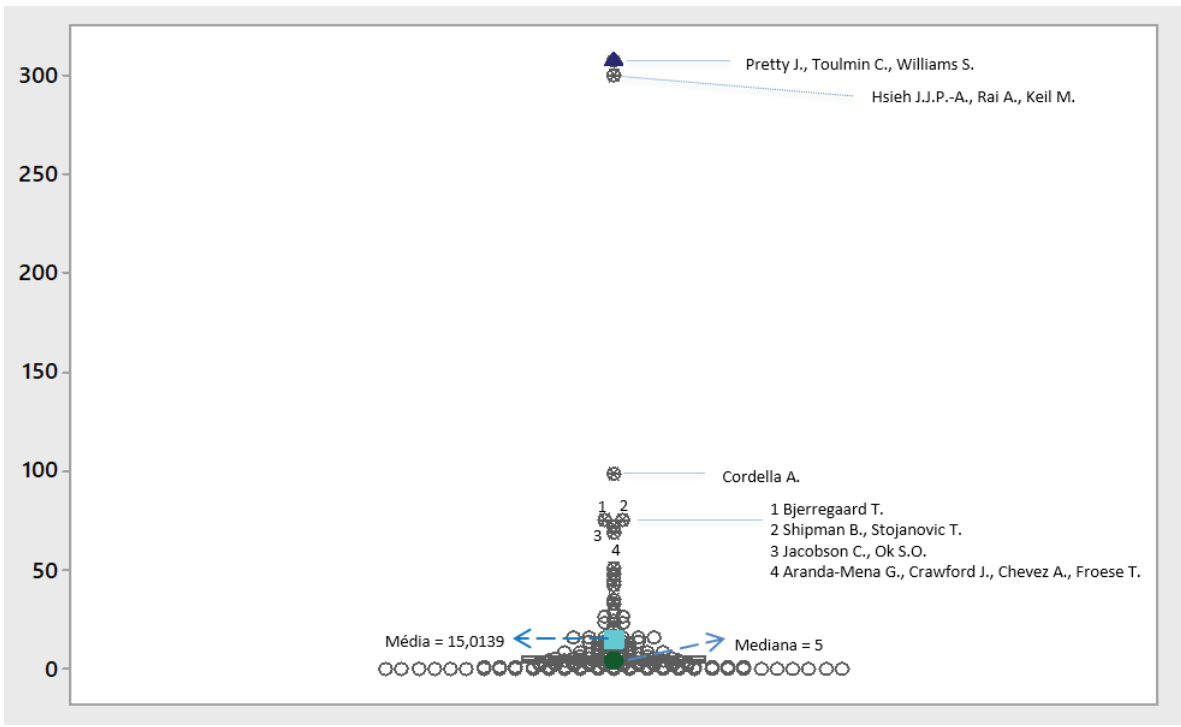

Fonte: Os autores

Quadro 5: Artigos analisados

\begin{tabular}{|c|c|c|c|c|c|c|}
\hline Autores & Título do Artigo & Periódico & Objetivo & $\begin{array}{l}\text { Método de } \\
\text { Pesquisa }\end{array}$ & $\begin{array}{l}\text { Barreiras de } \\
\text { Comunicação }\end{array}$ & $\begin{array}{c}\text { Canal de } \\
\text { Comunicação } \\
\text { Identificado }\end{array}$ \\
\hline $\begin{array}{l}\text { Pretty J., } \\
\text { Toulmin C., } \\
\text { Williams S. }\end{array}$ & $\begin{array}{c}\text { Sustainable } \\
\text { intensification in } \\
\text { African agriculture }\end{array}$ & $\begin{array}{l}\text { International } \\
\text { Journal of } \\
\text { Agricultural } \\
\text { Sustainability }\end{array}$ & $\begin{array}{l}\text { Mapear e disseminar os } \\
\text { processos e lições } \\
\text { aprendidas em } 40 \\
\text { projetos e programas de } \\
20 \text { países africanos que } \\
\text { realizaram agricultura } \\
\text { sustentável }\end{array}$ & $\begin{array}{l}\text { Análise de } \\
\text { projetos }\end{array}$ & $\begin{array}{l}\text { Falha na troca de } \\
\text { informação }\end{array}$ & Comunicação oral \\
\hline $\begin{array}{l}\text { Shipman B., } \\
\text { Stojanovic T. }\end{array}$ & $\begin{array}{l}\text { Facts, fictions, and } \\
\quad \text { failures of } \\
\text { Integrated Coastal } \\
\text { Zone Management } \\
\text { in Europe }\end{array}$ & $\begin{array}{c}\text { Coastal } \\
\text { Management }\end{array}$ & $\begin{array}{l}\text { O artigo resume as } \\
\text { conclusões de pesquisa } \\
\text { recentes sobre os niveis } \\
\text { de implementação da } \\
\text { gestão costeira na } \\
\text { Europa, com especial } \\
\text { referência à experiência } \\
\text { do Reino Unido }\end{array}$ & Estudo de caso & $\begin{array}{l}\text { Falta de boa } \\
\text { comunicação que } \\
\text { apoie a coordenaçãa } \\
\text { entre os sistemas } \\
\text { administrativos e os } \\
\text { diferentes setores }\end{array}$ & $\begin{array}{c}\text { Realização de } \\
\text { feedbacks gera } \\
\text { aumento de sucesso } \\
\text { da integração dos } \\
\text { sistemas }\end{array}$ \\
\hline $\begin{array}{c}\text { Jacobson C., Ok } \\
\text { S.O. }\end{array}$ & $\begin{array}{l}\text { Success factors: } \\
\text { Public works and } \\
\text { public-private } \\
\text { partnerships }\end{array}$ & $\begin{array}{l}\text { International } \\
\text { Journal of Public } \\
\text { Sector } \\
\text { Management }\end{array}$ & $\begin{array}{l}\text { Identificar fatores críticos } \\
\text { de sucessos e parcerias } \\
\text { público-privadas bem } \\
\text { sucedidas e projetos de } \\
\text { obras públicas }\end{array}$ & $\begin{array}{l}\text { Análise } \\
\text { qualitativa }\end{array}$ & $\begin{array}{c}\text { Coordenação entre os } \\
\text { sistemas } \\
\text { administrativos e os } \\
\text { diferentes setores }\end{array}$ & $\begin{array}{c}\text { Comunica ção aberta } \\
\text { como fator crítico de } \\
\text { sucesso }\end{array}$ \\
\hline $\begin{array}{l}\text { Rosacker K.M., } \\
\text { Olson D.L. }\end{array}$ & $\begin{array}{l}\text { Public sector } \\
\text { information system } \\
\text { critical success } \\
\text { factors }\end{array}$ & $\begin{array}{l}\text { Transforming } \\
\text { Government: } \\
\text { People, Process } \\
\text { and Policy }\end{array}$ & $\begin{array}{l}\text { Investigar fatores críticos } \\
\text { de sucesso do sistema de } \\
\text { informação do setor } \\
\text { público }\end{array}$ & Survey & $\begin{array}{l}\text { Falta de documentação } \\
\text { adequada dos fatores } \\
\text { críticos de sucessos }\end{array}$ & $\begin{array}{l}\text { Consulta e escuta } \\
\text { ativa de todas as } \\
\text { partes interessadas é } \\
\text { considerado um fator } \\
\text { crítico de sucesso }\end{array}$ \\
\hline $\begin{array}{l}\text { Mutti D., } \\
\text { Yakovleva N., } \\
\text { Vazquez-Brust } \\
\text { D., Di Marco } \\
\text { M.H. }\end{array}$ & $\begin{array}{l}\text { Corporate social } \\
\text { responsibility in the } \\
\text { mining industry: } \\
\text { Perspectives from } \\
\text { stakeholder groups } \\
\text { in Argentina }\end{array}$ & Resources Policy & $\begin{array}{l}\text { Demonstrar um esquema } \\
\text { para destacar com os } \\
\text { principios da teoria de } \\
\text { Stakeholders podem ser } \\
\text { usados como orientação } \\
\text { conceitual na resolução } \\
\text { de conflitos. }\end{array}$ & $\begin{array}{l}\text { Revisão de } \\
\text { literatura }\end{array}$ & $\begin{array}{l}\text { Comunicação } \\
\text { inadequada ( falta de } \\
\text { acesso à informaçãa, } \\
\text { sua integridade, } \\
\text { relevancia e precisão) }\end{array}$ & $\begin{array}{c}\text { Meios de publicização } \\
\text { das ações de } \\
\text { responsabilidade } \\
\text { social }\end{array}$ \\
\hline
\end{tabular}




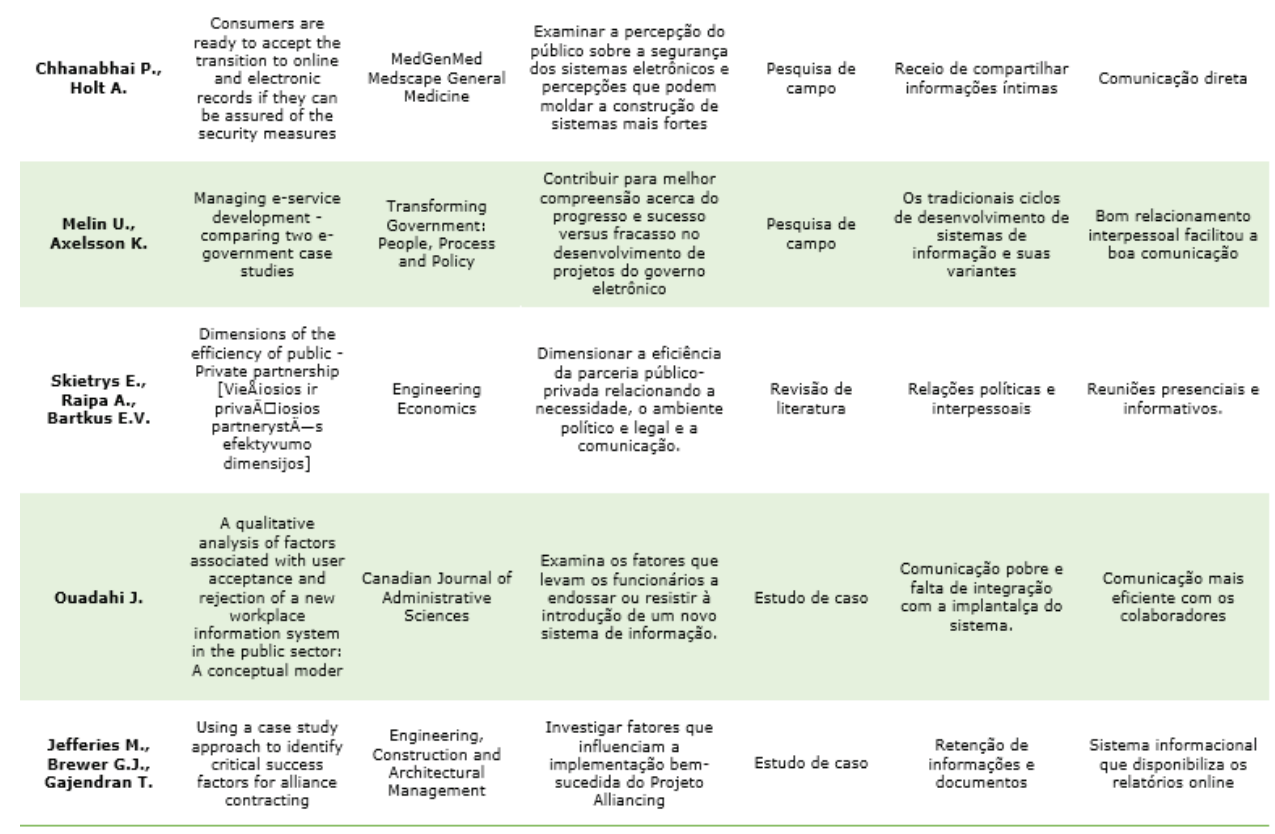

Fonte: Os autores.

\section{Considerações Finais}

O presente trabalho objetivou analisar a literatura internacional sobre comunicação em projetos do setor público, em um estudo quantitativo por meio da aferição dos índices de produção e difusão de conhecimento científico oriundos de um estudo bibliométrico, com uma amostra composta de 194 artigos, extraídos da base de dados Scopus, utilizando publicações registradas entre os anos de 2007 e maio de 2018.

Em média 19,4 artigos são publicados ao ano, tendo o ano de 2017 (14\% do total de publicações) o auge das mesmas. Os Estados Unidos obtiveram principal destaque nos campos abordados no presente artigo, sendo este o país com maior soma de artigos publicados, uma vez que os anos de 2015, 2010 e 2008 (6 publicações). A área de Ciências Sociais apresentou a maior quantidade de publicações sugere que os aspectos sociais do mundo humano são os principais fomentadores de pesquisas sobre comunicação em projetos do setor público principalmente os ligados ao E-Governe. 
A segunda área que mais abordou tal tema foi Ciências Médicas, no qual, os estudos desta enfocaram principalmente a qualidade dos serviços públicos quanto a promoção de prestação de serviços básicos como o fornecimento de água, medicamentos e prestação de serviços hospitalares. A área de Administração e Negócios como terceira, pode significar que o próprio governo público está investindo em pesquisas para o melhoramento do mesmo.

Além dos aspectos quantitativos, as análises qualitativas acerca dos artigos puderam demonstrar que nos 10 artigos, que atenderam ao critério, de estar acima da média 15,01 de citações, fora obtido um total 30 publicações inicialmente, e após refinou-se para aqueles foram referenciados por mais de 16 vezes e então submetidos à análise de menção no texto de barreiras de comunicação e se foram identificados canais de comunicação que viessem a minimizar os impactos das barreiras na comunicação dentro do projeto, chegando a 10 publicações, na qual relatam a comunicação do time do projeto como fator de importância, demonstrado também na revisão de literatura, quando os diversos autores citados relatam acerca do benefício e das consequências dos ruídos da comunicação, pois, as barreiras que foram identificadas apontam à aspectos desde a falta de interação entre os envolvidos, fatores sociais e de relacionamento, assim como a falta do registro da informação comunicada e a sua disseminação ao stakeholder.

A lacuna de pesquisa gira em torno da análise dos conceitos de comunicação identificados e se é apontado pela produção científica relacionada a esse tema aspectos relacionados às barreiras na comunicação e quais as principais, além de ter por principal contribuição do estudo uma análise realizada acerca do tema, a fim de oferecer como produto um esboço da arte acerca dos termos utilizados visando auxiliar os pesquisadores que possuem interesse de aprofundamento nos temas selecionados.

Portanto, as contribuições pretendidas com o presente trabalho, teve como premissa inicial oferecer como produto um levantamento do estado da arte acerca da comunicação em projetos públicos, visando auxiliar os pesquisadores que possuem interesse de estudo no tema selecionado, com a identificação das barreiras de comunicação levantadas e o canal de comunicação citado, levantando 
questionamentos acerca de trabalhos futuros que podem vir a ser empreendidos.

Ademais, pode-se perceber que o setor público é detentor de diversas particularidades quanto a forma de administrar-se, bem como seus anseios futuros, para tanto, a comunicação em projetos pode ser a chave para a concretização eficaz dos planos governamentais atendendo as crescentes expectativas populacionais.

No mais, os resultados do estudo foram limitados, pois, a quantidade de publicações analisadas e a coleta de dados oriunda de apenas uma base de dados, de forma que as conclusões não podem ser ampliadas e generalizadas. Novos horizontes podem ser explorados em futuros trabalhos como a análise de outras bases, quantidades amostrais maiores e englobar tanto o setor público quanto o privado, analisando como se relaciona, por exemplo, a literatura acerca das relações estabelecidas entre "stakeholders" com o "setor público" com foco na "comunicação" visando identificar as “barreiras de comunicação" estabelecidas dentro do projeto.

\section{REFERÊNCIAS}

ABREU, T. B.; BAZONI, M. C., 2016. Como superar barreiras na comunicação nas organizações. Revista Dito Efeito, v.7, n. 11, p. 74-94. Disponível em: < https://periodicos.utfpr.edu. br/de/article/download/4078/3496>. Acesso nov. 2018.

ADENFELT, M. (2010). Exploring the performance of transnational projects: Shared knowledge, coordination and communication. International Journal of Project Management, vol. 28, p. 529-538. Disponível em: < https://www.sciencedirect.com/science/article/abs/pii/ S026378630900115X>. Acesso em jul. 2018.

ALMEIDA, J. S. D., (2015). As boas práticas em Gerenciamento de Projetos no Setor Público. Revista Especialize On-line IPOG, v.1, n. 10. Disponível em: <https://www.ipog.edu.br/ download-arquivo-site.sp?arquivo=janaina-de-souza-dantas-almeida-119392.pdf $>$. Acesso em jan. 2019.

ANDERSSON, A. (2016). Communication barriers in an interorganizational ERP-project. International Journal of Managing Projects in Business, vol. 9, issue: 1, pp. 214-233. Disponível em: <https://www-emeraldinsight-com.ez98.periodicos.capes.gov.br/doi/pdfplus/10.1108/ IJMPB-06-2015-0047>. Acesso em jul. 2018.

BOGDAL, M. (2013). Communication management in public sectors: the case of the Polish energy sector. Revista Comunicação Pública, vol. 8 n. 14. Disponível em: <https://journals. openedition.org/cp/553\#tocto1n1>. Acesso em jul. 2018.

CEZAR, L. C. (2018). Reflexões sobre a comunicação em políticas públicas: proposta de um modelo de avaliação da comunicação governamental. Revista de Administração Pública, v. 
52, n. 1, p. 57-70. Disponível em: <http://www.scielo.br/pdf/rap/v52n1/1982-3134-rap-52-01-52. pdf $>$. Acesso em jan. 2019.

CHUEKE, G. V. ; AMATUCCI, M. (2015). O que é bibliometria? Uma introdução Fórum. Revista eletrônica de negócios internacionais, vol. 10, n. 2, p. 1-5. Disponível em: <http:// web.b-ebscohost-com.ez98.periodicos.capes.gov.br/ehost/pdfviewer/pdfviewer?vid=1\&sid=8 86c24a5-e263-408d-9ae7-d3f1d2aefc23\%40pdc-v-sessmgr02>. Acesso em jul. 2018.

CYGANCZUCK, M. S.; JUNIOR, R. M.; JUNIOR, J. E. P. (2018) Percepções dos gerentes de projeto em relação às falhas e barreiras de comunicação. GEPROS. Gestão da Produção, Operações e Sistemas, vol. 13, n. 1, p. 56-68. Disponível em: <https://revista.feb.unesp.br/ index.php/gepros/article/view/1992/822>. Acesso em jan. 2019.

ČULO, K ; SKENDROVIĆ, V. (2010). Communication management is critical for project success. Informatologia, vol. 43 (3), p.228-236. Disponível em: < https://search-ebscohost-com. ez98.periodicos.capes.gov.br/login.aspx?direct=true\&db=lih\&AN=55506529\&site=ehost-live $>$. Acesso em jul. 2018.

FILHO, M. X. D. C. (2015). Administração pública brasileira. Latin American Journal of Business Management, vol. 6, N.1. Disponível em: <http://www.lajbm.net/index.php/journal/ article/view/243>. Acesso em jul. 2018.

GALBRAITH, J. R. (1995). Designing organizations: an executive briefing on strategy, structure, and process. San Francisco: Jossey-Bass Publishers.

GIL, A. C. (2006). Gestão de pessoas: enfoque nos papéis profissionais. 1ª ed., 6. Reimp., São Paulo, Atlas, p. 74-77.

HEDLER, H. C. et al (2015). Barreiras à comunicação organizacional: um estudo emu ma organização pública do governo do Distrito Federal. Revista de Estudos da Comunicação, v. 16, n. 40, p. 165-181. Disponível em: < https://core.ac.uk/download/pdf/79177610.pdf>. Acesso em nov. 2018.

KERZNER, H. (2009). Project management: a systems approach to planning, scheduling, and conrolling. John Wiley \& Sons, Inc., Hoboken, New Jersey - 10th ed. Disponível em: $<$ http://honestyets.pbworks.com/f/Project+Management+-+A+Systems+Approach+-+10thEd. pdf $>$. Acesso em jul. 2018.

LING, F. Y. Y.; MA, Y., (2014). Effect of competency and comnunication on project outcomes in cities in China. Habitat International, v. 44, p. 324-331. Disponível em: < https://www. sciencedirect.com/science/article/pii/S0197397514001118>. Acesso em dez. 2018.

MOLENAAR, K. R.; SONGER, A. D.; ASCE, A. M. (1998). Model for public sector designbuild project selection. Journal of Construction Engineering and Management, vol. 124 (6), p. 467-479. Disponível em: < https://ascelibrary.org/doi/10.1061/\%28ASCE\%2907339364\%281998\%29124\%3A6\%28467\%29>. Acesso em jul. 2018.

MORRIS, S.; et al. (2002). A visualization system for exploring document databases for technology forecasting, Computer. Computers \& Industrial Engineering, vol. 43, n. 4. Disponível em: < https://elibrary.ru/item.asp?id=6410887>. Acesso em jul. 2018.

NORTON, M. J. (2001). Introductory Concepts in Information Science. Information Today, Inc.,. 
PMI (2017). Um guia do conhecimento em gerenciamento de projetos (Guia PMBOK®). $6^{\text {a }}$ ed. Project Management Institute, Inc..

QUADROS, A. S.; CARVALHO, H. G., (2012). O gerenciamento da comunicação de projetos públicos: como adaptar os processos do PMBOK/PMI à realidade da administração pública. Revista Brasileira de Planejamento e Desenvolvimento, v. 1, n. 1, p. 56-60. Disponível em: < https://periodicos.utfpr.edu.br/rbpd/article/view/3097/2115>. Acesso em jan. 2019.

ROMAN, A. R. (2009). Organizações: um universo de discursos bem-ditos, mal-ditos e não-ditos. In: Kunsch, M. M. K. (Org.). Comunicação Organizacional: linguagem, gestão e perspectivas, volume 2. São Paulo: Saraiva. p. 125-157.

SILVA, R. C. D. et al. (2018). A relação entre comunicação e comprometimento nas organizações. Rev. Adm. UFSM, Santa Maria, v. 11, n. 6, p. 102-116. Disponível em: < https://www. researchgate.net/profile/Rodrigo_Cunha_Da_Silva/publication/325598008_A_relacao_entre_comunicacao_e_comprometimento_nas_organizacoes/links/5b17ce43458515cd61a9d64a/A-relacao-entre-comunicacao-e-comprometimento-nas-organizacoes.pdf $>$. Acesso em jul. 2018.

SCOPUS. What is scopus. (2018). Scopus site. Disponível em:< https://www.elsevier.com/ solutions/scopus>. Acesso em jul 2018.

SMIT, M. C. et al. (2017). Email communication in project management: A bane os a blessing? South African Journal of Information Management, v. 19(1), n. 826. Disponível em: <https:// sajim.co.za/index.php/sajim/article/view/826/1135>. Acesso em jul. 2018.

SOUZA, M. B. S.; RODRIGUES, A. A., (2012). O processo de comunicação no projeto PROFISCO/RN - Brasil. Revista de Gestão de Projetos, v. 3, n. 3, p 88-108. Disponível em: <http:// www.revistagep.org/ojs/index.php/gep/article/view/80/308>. Acesso em jan. 2019.

VIEIRA, A. M. Cultura organizacional em instituições de ensino: mapeamento e análise descritivo-interpretativa da produção acadêmica (1990-2005). 2007. 237f. Tese (Doutorado em Educação) - Universidade Estadual Paulista (UNESP), Marília, 2007.

VOSVIEWER, (2019). Welcome to VOSviewer. VosViewer site. Disponível em: <http://www. vosviewer.com/>. Acesso em fev. 2019.

YAP, J. B. H.; ABDUL-RAHMAN, H.; CHEN, W., (2017). Collaborative model: Managing design changes with reusable project experiences through project learning and effective communication. International Journal of Project Management, v. 35, n. 7, 1253-1271. Disponível em: $<$ https://www.sciencedirect.com/science/article/pii/S0263786316302137>. Acesso em jan. 2019.

ZULCH, B., (2014). Communication: the foundation of Project management. Procedia Technology, v. 16, p. 1000-1009. Disponível em: < https://www.sciencedirect.com/science/article/ pii/S2212017314002813>. Acesso em dez. 2018.

Recebido em: 13-2-2019

Aprovado em: 13-11-2020

Avaliado pelo sistema double blind review.

Editor: Coordenação do PPGA/UMESP

Disponível em http://mjs.metodista.br/index.php/roc 